\title{
All Internal Bone Transport: Use of a Lengthening Nail and Double Plating for Management of Femoral Bone Loss
}

\author{
Jonathan Wright ${ }^{1}$, Peter Bates ${ }^{2}$, Nima Heidari ${ }^{3}$, Alexandros Vris ${ }^{4}$
}

\begin{abstract}
Background: A variety of techniques for management of segmental femoral bone loss have been described, each with different advantages and challenges during treatment. The development of motorized lengthening nails has provided a potential for all internal bone transport, avoiding some of the difficulties with external fixation in the femur. At present, there is a limited published literature on experiences in this technique. Aim: The development of this technique aimed to overcome the difficulties previously reported for internal bone transport in the femur, particularly varus deformity and joint stiffness.

Technique: We describe the technique of double plating with bone transport utilizing a magnetic lengthening nail to manage segmental femoral bone loss. The benefits of the technique are discussed, along with specific challenges and lessons that have been learned through experience of internal bone transport.

Conclusion: Use of a magnetic lengthening nail and double plating as a method of all internal bone transport provides an option for the management of massive femoral bone loss, while avoiding some of the challenges that have been reported with the existing techniques.

Clinical significance: This technique provides an additional method in the armamentarium of the trauma or limb reconstruction surgeon treating massive femoral bone loss.

Keywords: Bone loss, Bone transport, Femur, Lengthening nail.

Strategies in Trauma and Limb Reconstruction (2019): 10.5005/jp-journals-10080-1431
\end{abstract}

\section{BACKGROUND}

Bone loss following treatment of trauma, tumour, or infection remains a challenge for the treating orthopaedic surgeon. A number of techniques have been described to manage deficiencies, including the induced membrane technique, ${ }^{1}$ vascularized fibula grafting, ${ }^{2}$ acute shortening then lengthening, ${ }^{3}$ and bone transport utilizing monolateral, ${ }^{4,5}$ Ilizarov $_{,}{ }^{6,7}$ or hexapod fixators. ${ }^{8}$

In the femur, external fixators are challenging to manage for the patient; soft-tissue tethering and pin site irritation may be more problematic than in the tibia due to the size and shape of the soft-tissue envelope. ${ }^{9,10}$ Various methods have been described to minimize the time in external fixation for the femur, including lengthening over a nail, ${ }^{3,11}$ lengthening and then nailing, ${ }^{12}$ and lengthening and then plating. ${ }^{13}$

More recently, with the development of motorized lengthening nails, the potential for all internal bone transport has been suggested, either through use of a custom nail ${ }^{14}$ or a lengthening nail with "plateassisted bone segment transport" (PABST) to maintain length and alignment, which has been used in both femur and tibia. ${ }^{15,16}$ In the femur, there have been anecdotal (unpublished) reports of difficulty with varus deformity during transport. We describe a modification of this technique, adding a medial submuscular plate to control alignment and allow earlier weight-bearing and more aggressive knee mobilization, along with a retrograde, pre-distracted nail with an aim to improve docking site accuracy.

\section{Patients and Technique}

Our indication for this technique is segmental diaphyseal bone loss in the femur, usually following an open fracture. This injury is almost invariably a result of polytrauma, and the concomitant injuries contribute to the planning and timing of the procedures
${ }^{1}$ Department of Paediatric Orthopaedics and Limb Reconstruction, Royal National Orthopaedic Hospital, Stanmore, Middlesex, UK

${ }^{2-4}$ Department of Trauma and Orthopaedics, Royal London Hospital, Barts Health NHS Trust, London, UK

Corresponding Author: Alexandros Vris, Department of Trauma and Orthopaedics, Royal London Hospital, Barts Health NHS Trust, London, UK, e-mail: avris@nhs.net

How to cite this article: Wright J, Bates $\mathrm{P}$, Heidari N, et al. All Internal Bone Transport: Use of a Lengthening Nail and Double Plating for Management of Femoral Bone Loss. Strategies Trauma Limb Reconstr 2019;14(2):94-101.

Source of support: Nil

Conflict of interest: None

described below. The technique is described in depth relating to the first patient, and the early outcomes are discussed in the subsequent two.

\section{Case 1}

A 25-year old man was brought to the Major Trauma Centre following a collision with a truck, while on his motor bike. He had no previous medical history and was a nonsmoker. His injuries included open Gustilo grade IIIA right femoral fracture, along with fracture of the right acetabulum, right tibial pilon, right patella, left-sided posterior cruciate ligament $(\mathrm{PCL})$ rupture, and a grade Il liver laceration.

\section{First Stage}

In line with the current guidelines, a thorough debridement of the open fracture was performed, leaving only healthy bleeding 
tissues behind. Significant bone loss was encountered, so steps were taken at the first debridement for subsequent reconstruction. The bone ends were cut level with a saline-cooled oscillating saw to allow for subsequent bone transport and good bony apposition with eventual docking. The dead space was filled with a custommade antibiotic-loaded polymethymethacrylate (PMMA) cement spacer, ${ }^{17}$ using revision type cement with added vancomycin and gentamycin. The femur was then fixed with the longest possible anatomic lateral large fragment locking plate in bridging mode, leaving a long segment of bone proximal to the defect free of fixation (Fig. 1). Three locking screws were used in the proximal segment and five screws distally. Care was taken to restore length, alignment, and rotation of the femur to the best extent that was possible. It was noted that $160-\mathrm{mm}$ bone loss was present at this time. The skin was then closed primarily. At the same sitting, the patella fracture was fixed and a spanning external fixator applied for the pilon fracture. Postoperatively the patient was allowed to mobilize the knee gently but remained toe-touch weight bearing.

When the soft tissues allowed, the pilon fracture was treated with open reduction and internal fixation. The acetabular fracture, $\mathrm{PCL}$, and liver lacerations were managed nonoperatively.

\section{Second Stage}

Once the associated injuries had been addressed, the soft tissues were amenable and there was no evidence of active infection, the second stage was started. This is not usually less than 3-4 weeks after the first stage; in this case, it was at week 10. Careful planning was required for implant selection according to the size of the defect and the requirements of the planned bone transport.

The cement spacer was first removed through the original lateral incision. A short straight universal femoral Precice nail (NuVasive, San Diego, USA) was pre-distracted on table with the precice fast distractor (Fig. 2) and inserted in the femur in a

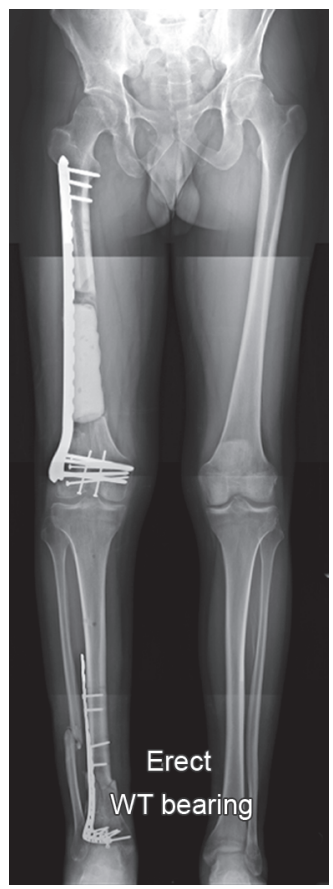

Fig. 1: The femur is fixed with the longest possible anatomic lateral large fragment locking plate in bridging mode, leaving a long segment of bone proximal to the defect free of fixation, with an antibiotic-loaded polymethymethacrylate spacer in the $16-\mathrm{cm}$ defect retrograde fashion. Two screws from the distal part of the lateral locking plate were changed in order to allow passage of the guide wire and reamers as they would have blocked the intended course of the nail. These screws were replaced with either slightly different trajectories or in different plate holes at the end of the procedure to achieve the desired purchase.

Preoperative planning for nail selection allows use of the shortest implant that, when fully pre-distracted, can cross the defect and be locked in the proximal segment. The smallest diameter available $(8.5 \mathrm{~mm})$ was preferred in order to facilitate the transport segment sliding on the nail without jamming. For this reason, the bone canal was reamed to the largest diameter possible and at least $2 \mathrm{~mm}$ above the size of the nail. After reaming, the nail was temporary inserted in its final position in order to confirm the size and position. Then, it was backed out of the proximal segment to allow for the corticotomy.

Next, the access for applying the medial plate was prepared. A 5-cm anteromedial approach to the proximal femur was performed, following the intermuscular plane between tensor fasciae lata and sartorius, staying just lateral to sartorius. It is recommended that the skin incision is made $3-4 \mathrm{~cm}$ medial to the intermuscular plane, as this allowed easier retraction of the skin for medial to lateral drilling during the application of the medial plate proximal screws that followed (Fig. 3). The limits of the incision can be marked with intraoperative fluoroscopy. The desired extent was from the less trochanter, where the proximal end of the medial plate will lie, to $2 \mathrm{~cm}$ below the most distal of the proximal locking screws of the lateral plate, where the corticotomy for bone transport was planned (Fig. 4). Blunt finger dissection was performed between the lateral edge of sartorius and through the medial fibres of rectus femoris. A Bristow elevator is then used to develop an extraperiosteal plane through vastus intermedius and beneath vastus medialis to expose the medial edge of the proximal femur. The periosteum was left intact. Careful placement of Hohman retractors keeps the vastus medialis between the femoral vessels and the level of dissection. The lateral circumflex femoral artery and its branches can be palpated at the proximal portion of the wound. The artery was protected although small branches were necessary to be coagulated with diathermy.

A low-energy femoral corticotomy was performed with a 3.5-mm drill and osteotomes just distal to the proximal plate locking

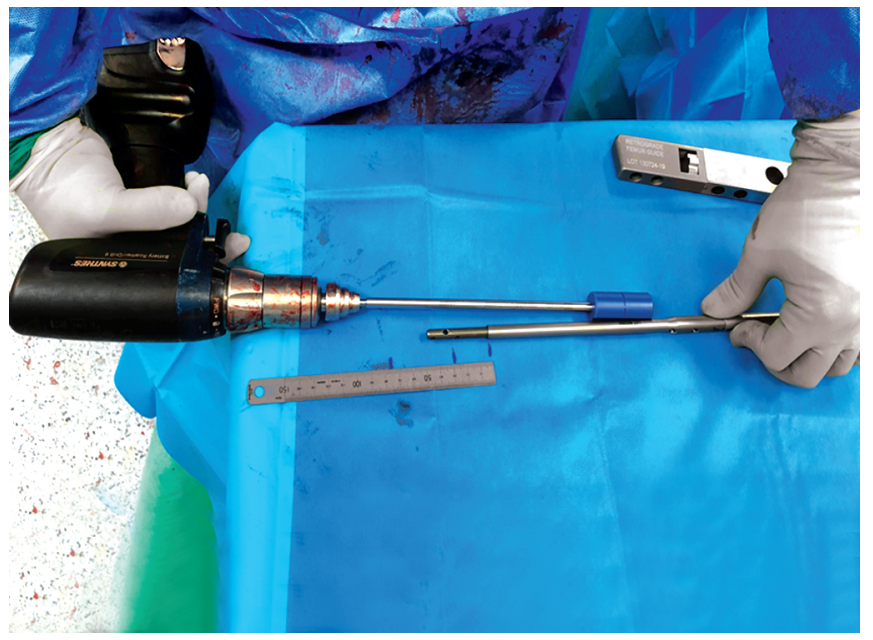

Fig. 2: A short straight universal femoral Precice nail is pre-distracted on table with the fast distractor 


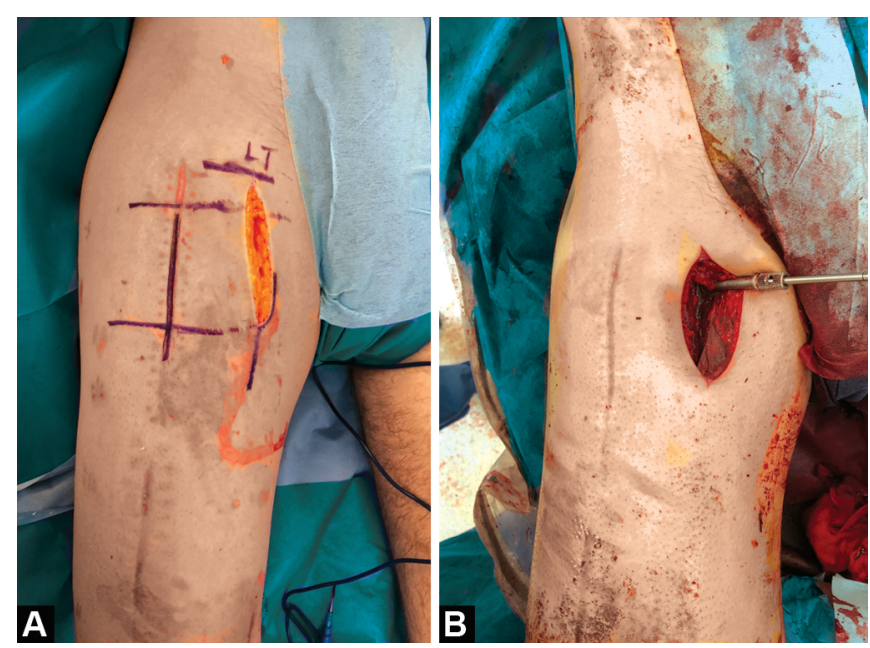

Figs $3 A$ and B: (A) Proximal-medial incision $3-4 \mathrm{~cm}$ medial to the intermuscular plane; (B) Drilling through proximal-medial incision

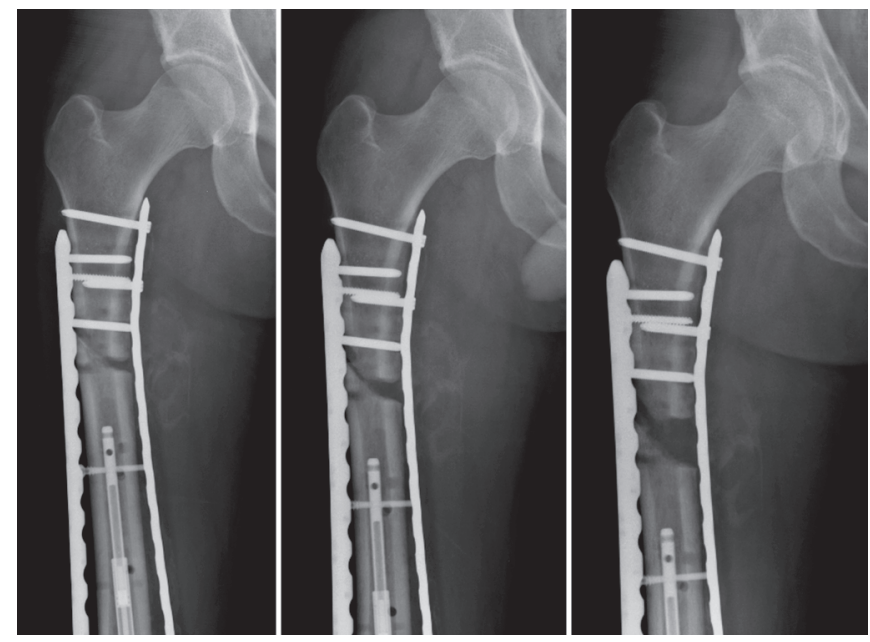

Fig. 5: By shortening the nail, the free segment of the femur is transported

screws, creating a free-floating femoral shaft segment. The nail was advanced into this segment and locked proximally and distally in the femoral condyles with one interlocking bolt in each end. Distally the nail can additionally be locked through the plate with a locking screw from the large fragment plating set, as the screws are of same size as the locking bolts of the nail $(5 \mathrm{~mm})$. This technique provided additional anchoring of the nail in the distal femoral segment as well as to the locking plate.

The distance from the medial femoral epicondyle was measured, and a narrow straight large fragment plate of the appropriate length was pre-contoured. An anteromedial distal femoral $4-\mathrm{cm}$ incision allowed retrograde insertion of the plate in a submuscular, extraperiosteal plane. The plate was visualized through the proximal anteromedial incision and advanced on the proximal femur with at least two holes being above the level of the corticotomy. It was then fixed with two screws in each end. All the wounds were irrigated thoroughly, and the soft tissues were closed in layers.

\section{Postoperative Care}

The nail external remote controller was programmed to shorten the nail by $3 \times 0.33 \mathrm{~mm} /$ day, starting 7 days after the corticotomy. While

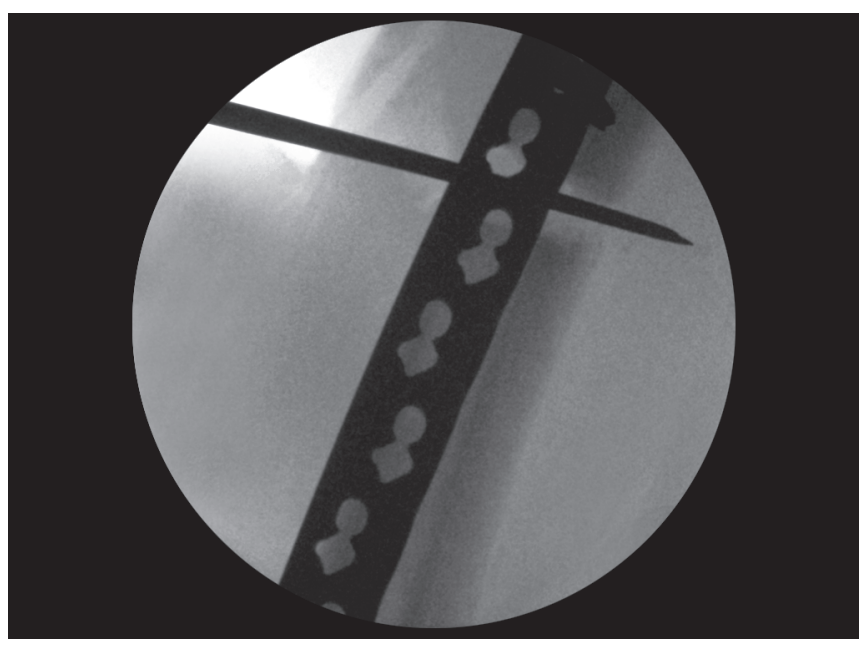

Fig. 4: The osteotomy is performed around $2 \mathrm{~cm}$ below the most distal of the proximal screws of the lateral plate

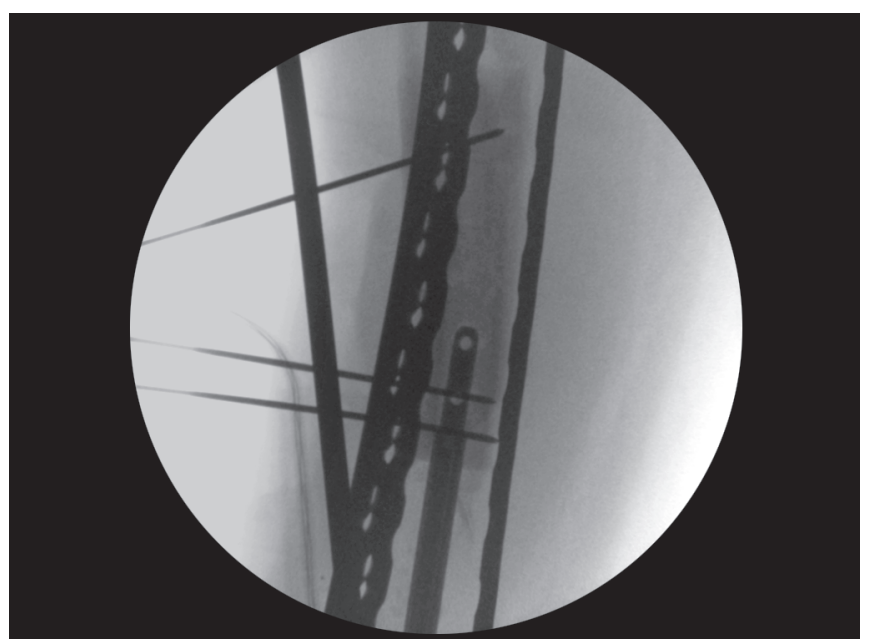

Fig. 6: The transport segment is held in place with 2 Kirschner wires through the lateral plate, and the nail is unlocked proximally

shortening the nail, the free segment of the femur is transported by sliding on the nail toward the distal femoral segment, until it docks (Fig. 5). This patient was kept touch weight bearing throughout the transport process, with gentle physiotherapy. This was changed in subsequent cases due to the development of knee stiffness (discussed below).

\section{Subsequent Procedures}

As the stroke length of the nail was shorter than the total transport distance, subsequent procedures were required. For defects greater than $50 \mathrm{~mm}$, this exceeds the stroke length for the shorter sizes of Precice nail that are most commonly used for this technique. In fact, only around $45 \mathrm{~mm}$ can be safely used, as there is a risk of the motor disengaging from the internal lengthening rod when the nail is pre-distracted to its maximum length. For this patient, three successive transport periods were required.

For the second transport, the nail was re-lengthened in situ with the fast distractor after being unlocked proximally, while the transport segment was held in place with two Kirschner wires through the lateral plate (Fig. 6). The in situ distraction can be achieved either transcutaneously (Figs 7 and 8) or through a skin 

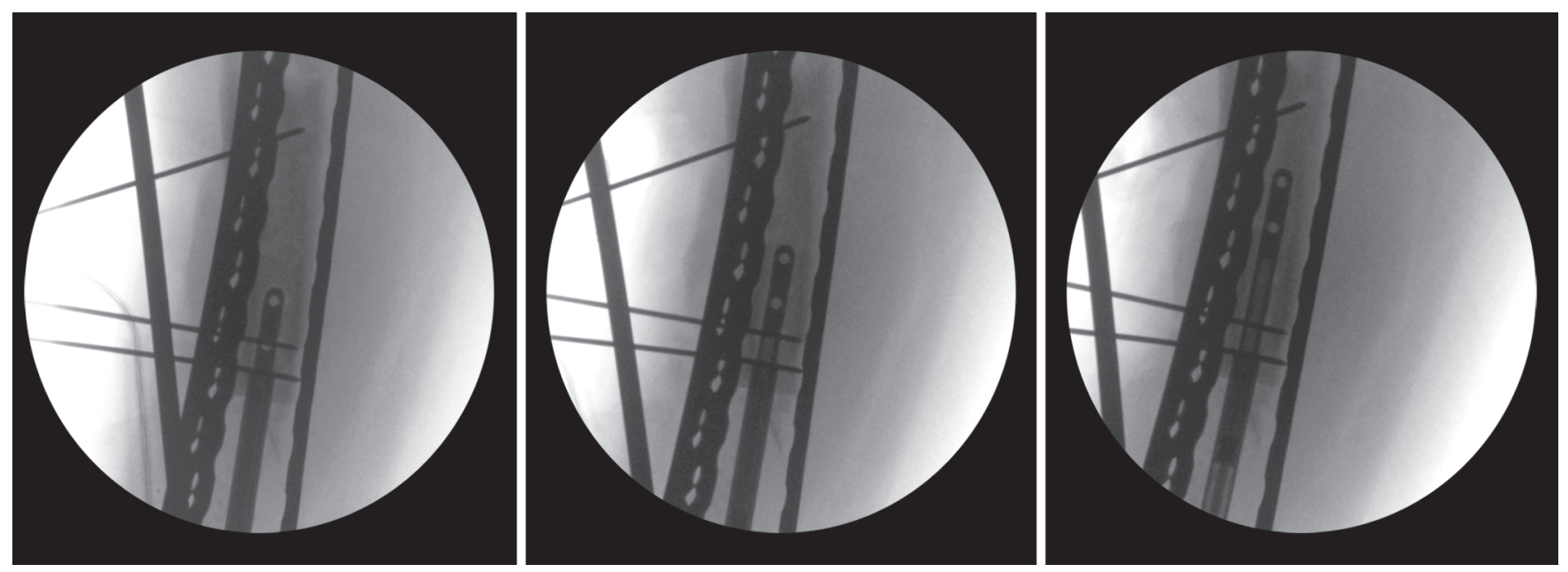

Fig. 7: Distraction of the nail in situ with the fast distractor

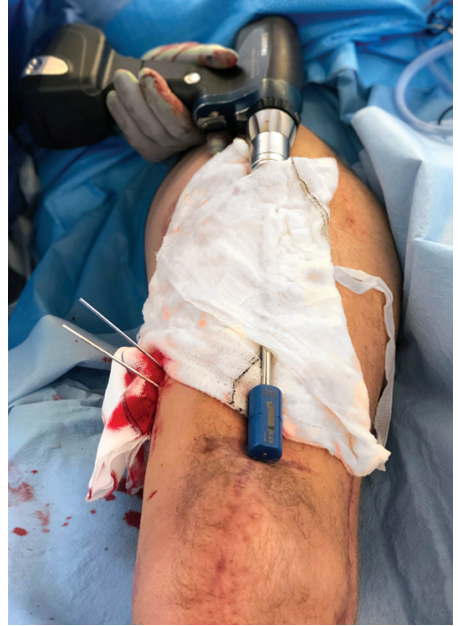

Fig. 8: Noninvasive transcutaneous distraction of the nail in situ with the fast distractor

incision in order to bring the magnet of the fast distractor close to the magnet of the nail (Fig. 9, used when the nail was exchanged). If the fast distractor does not work with the nail in place, then the nail would have to be either removed and redistricted on table as in the first stage or exchanged to a new one. Following re-distraction, the nail was then relocked in the transport segment. Shortening of the nail was recommenced postoperatively at day 1, at the same rate as previously.

It is recommended that before proceeding, the estimated position of the nail after re-distraction is defined. In case there is suspicion that the tip of the nail is going to be in a suboptimal (too proximal) position, then the nail should be exchanged to a shorter implant. For these reasons, the nailing instrument tray and a backup nail should be available during this stage. The stage can be repeated for even longer defects. At the third period of transport, the nail needed to be removed and replaced with a shorter nail, which had been pre-distracted.

At completion of the third transport, the transport segment had not completely docked, so a decision was made to graft the remaining $15-\mathrm{mm}$ gap at the time of nail removal. Total transport time at this point was 165 days. Nail removal was performed 5 months subsequently, at which point the medial docking site was

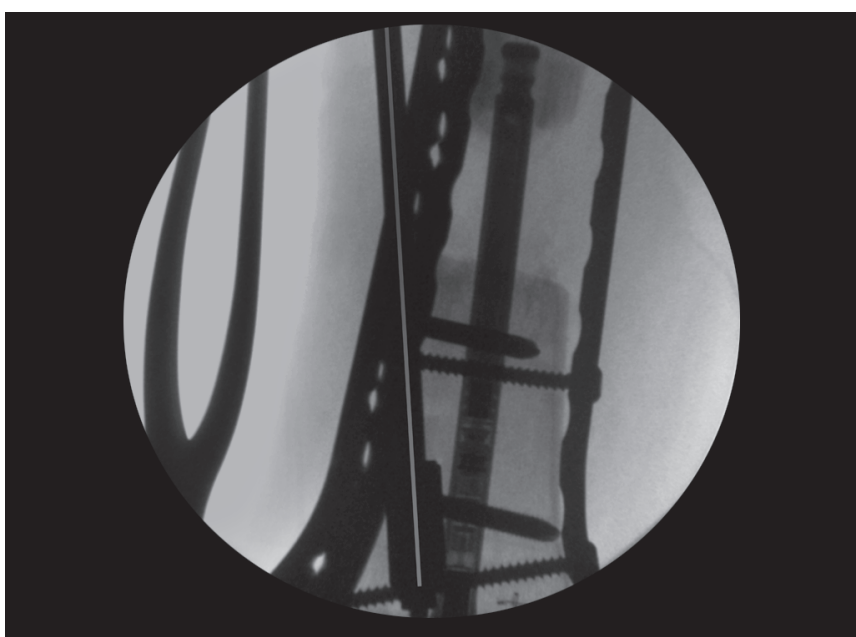

Fig. 9: If transcutaneous distraction is not possible, an incision can be used to position the magnet of the fast distractor as close as possible to the magnet of the nail. The nail and the fast distractor should preferably be as close to parallel as possible (fast distractor is highlighted with blue line)

seen to have united, although the lateral docking site was packed with iliac crest bone graft. The transport segment was locked to the plate at this point (Figs 10 and 11). Due to knee stiffness, a manipulation under anaesthesia was performed at the time of nail removal. At this point, an iatrogenic proximal tibial fracture was created, which necessitated plate fixation. This further delayed the time for full weight bearing, until the proximal tibial fracture allowed. The patient was monitored regularly radiographically, in order to assess the progress of healing at the docking site and the consolidation of the regenerate.

\section{Case 2}

A 37-year-old man was involved in a high-speed head-on road traffic collision. He sustained bilateral open (Gustilo 3A) femoral fractures. Additional injuries included bilateral rib fractures with associated pneumothoraces, left knee medial collateral ligament (MCL) avulsion, right-sided patella fracture, olecranon fracture, undisplaced talus fracture, right hallux distal phalanx fracture, left subclavian pseudoaneurysm, and subdural and mesenteric hematomas. No past medical history. 


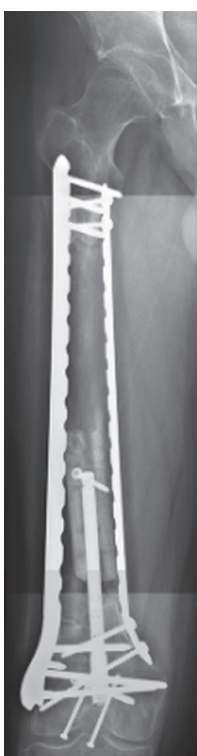

Fig. 10: Anteroposterior radiograph of femur demonstrating completed transport with regenerate before nail removal

Following initial debridement and damage control external fixation on day 0 , the patient returned to theatre on day 1 for further debridement. The left femur was internally fixed with a retrograde nail. The right femur was found to have $70 \mathrm{~mm}$ bone loss and so had a cement block and an anatomic lateral femoral plate applied as per the technique above. The olecranon was fixed at day 4, and the remaining orthopaedic injuries were managed nonoperatively.

The second stage was performed at week 8 in the same manner as for case 1, although full weight bearing and aggressive physiotherapy were commenced from day 1 of transport. At week 15 , the nail was re-distracted in situ, and the second transport period continued until docking of the transport segment was achieved after 84 days transport time. Range of motion was maintained throughout the transport process.

\section{Case 3}

A 31-year-old man was involved in a road traffic collision, when he swerved to avoid a head-on collision, hitting a wall. He sustained an isolated, open Gustilo grade IIIA femoral fracture. The fracture was treated out of area with debridement and an external fixator and then repatriated to the Major Trauma Centre for definitive treatment, with $80 \mathrm{~mm}$ bone loss. At day 7, a cement spacer was placed along with an anatomic lateral femoral plate, as the previous technique. The second stage was commenced at week 8 with the same method as described above. At week 15 , the nail was re-distracted in situ, and the second transport period continued until docking of the transport segment was achieved after 90 days transport time. Range of motion was maintained throughout the transport process (Figs 12 and 13).

A summary of the patient characteristics is seen in Table 1. Cases 2 and 3 are still consolidating at the docking site and will have an elective removal of the Precice nail at around 2 years post-insertion.

\section{Discussion}

A range of techniques exists for the management of bone loss in the femur, each with their own risk profile. For smaller defects,

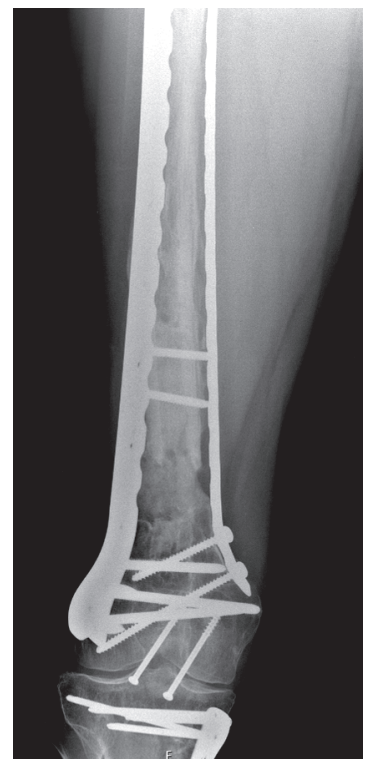

Fig. 11: Anteroposterior radiograph of femur demonstrating completed transport with regenerate after nail removal, locking of the transport segment on the plate and docking site autologous iliac crest bone grafting

acute shortening then lengthening is likely a more predictable option ${ }^{3,18,19}$; however, this needs to be weighed up with the limits of soft-tissue shortening. ${ }^{20,21}$ Bone transport may be more suitable for larger defects but equally comes with a greater potential for complications. External fixation in the femur is frequently difficult for the patient to manage, hence the push for development of methods to shorten time in fixator or avoid external fixation ent irely. $3,5,11,13,14,16$

Lengthening nails have been developing over recent years with progression from the initial mechanical methods of lengthening to newer motorized devices, ${ }^{22-24}$ affording greater precision of correction ${ }^{25,26}$ and an ability to both lengthen and shorten as required. ${ }^{27}$ These provide an attractive option, particularly in the femur, as they have been shown to have greater patient satisfaction, with a favourable complication profile in comparison with external methods for limb lengthening. ${ }^{10,28}$

Bone transport is challenging to achieve with the use of lengthening nails. There are currently designs for custom transport nails with others in development, although these still have limited control of the transport fragment. ${ }^{14}$ Reports of use of PABST are encouraging developments in the technique, although varus deformity is a difficulty reported anecdotally and discussed in the limited literature available. ${ }^{15,16}$

We began to use the medial plate as a means of better controlling varus deformity, with the approach as described in the use by Nayagam ${ }^{13}$ et al. to shorten time in frame for femoral lengthening patients. The stability afforded by the double plate also allows full weight bearing with crutches for support during the bone transport process. The first patient we described was toe-touch weight bearing with gentle physiotherapy exercises throughout the transport phase. Significant knee stiffness (range $0-50^{\circ}$ ) and poor muscle recovery were seen at the end of the transport process. A gradual increase to full weight bearing was planned to start after the docking site procedure, when the iatrogenic proximal tibia fracture occurred during knee manipulation under anesthesia (MUA). Therefore, for the following patients, the postoperative rehabilitation protocol was changed to postoperative full 

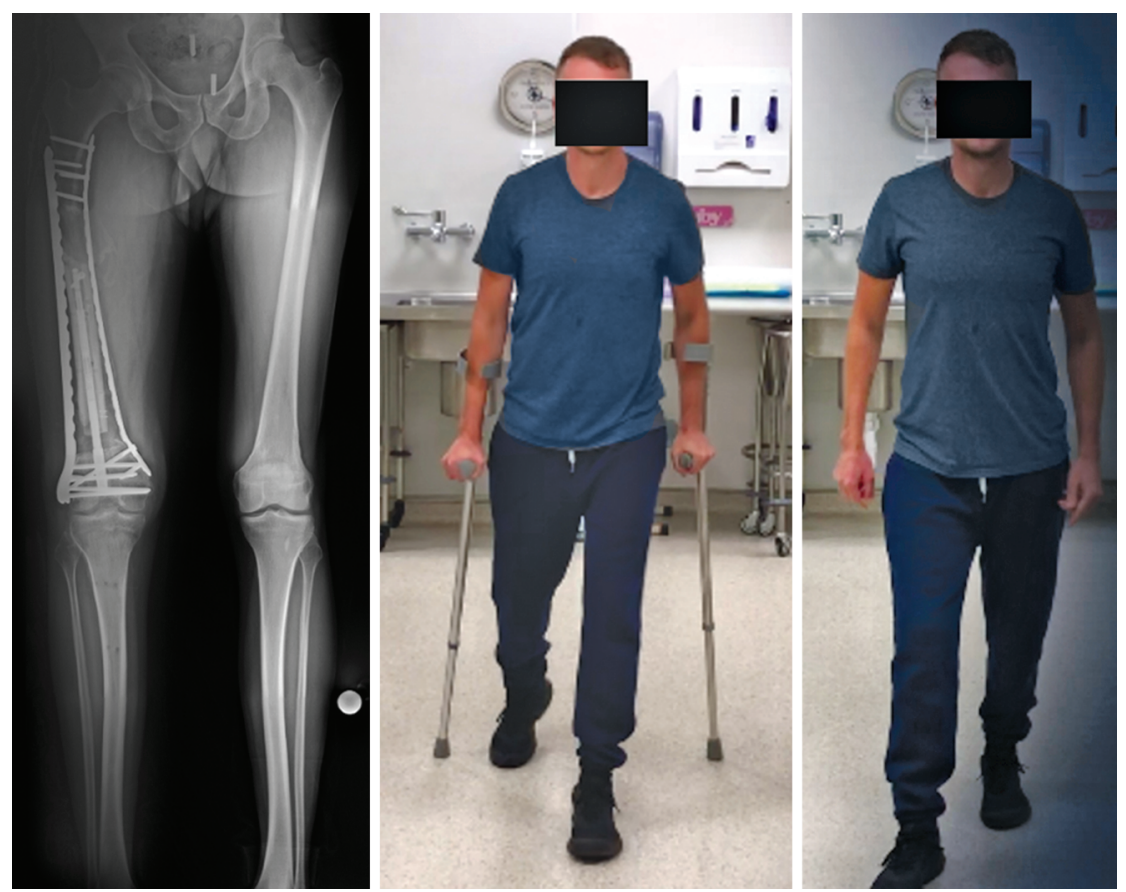

Fig. 12: Radiograph and clinical photograph demonstrating full weight bearing during bone transport with and without crutches
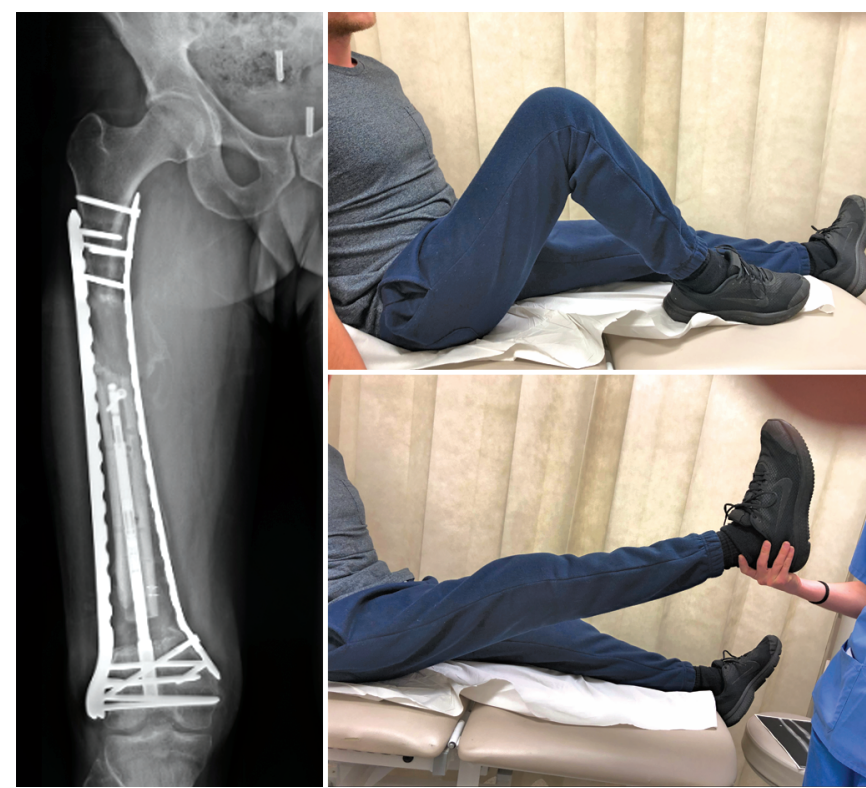

Fig. 13: Radiograph and clinical photographs demonstrating knee range of movement during bone transport

weight bearing with crutches for support and aggressive knee physiotherapy for range of movement and muscle strengthening as soon as the soft tissues allowed. With this protocol, both subsequent patients achieved full knee range of movement and full weight bearing during the bone transport phase. This is valuable for early return to normal function and independence in daily tasks and also valuable in the patient groups where compliance in weight-bearing restriction was not strictly followed. The early knee aggressive mobilization that the medial plate allows may help avoid knee stiffness (Figs 12 and 13), and the potential need for surgery to mitigate this, such as quadricepsplasty, that was present in the single-plate femoral PABST group of patients. ${ }^{16}$
The choice of antegrade or retrograde nail should also be considered. ${ }^{29}$ The direction of transported segment is largely determined by the pattern of bone loss. For distal bone loss, where possible our preference was to use a retrograde (pulling) technique, which allowed greater control of the final docking site position. An antegrade (pushing) technique comes with the risk of the straight nail transporting along a femur fixed with an anatomic plate with a normal anterior bow. This can allow the transport fragment to migrate anteriorly as it comes to dock with the distal fragment, if not carefully controlled at the time of initial fixation.

The addition of a supplementary medial plate is not without its own risks. There is a learning curve to the less familiar approach to the medial proximal femur, which needs to be considered. Corticotomy with drill and osteotome is also more challenging with metalwork obstructing access, which is mitigated by performing the corticotomy through the proximal-medial incision before the application of the medial plate. There is also a theoretical risk to the vascularity of the transport fragment with bilateral plating, particularly when the nail already disrupts the endosteal supply. In order to avoid this, the use of a submuscular, extraperiosteal locked plate aims to limit disruption of the lateral and medial periosteum.

A retrieval analysis suggests that the newer designs of Precice nail have intact and functioning internal mechanisms, following one period of lengthening, suggesting repeated use may be appropriate. ${ }^{30}$ Certainly, case reports for repeat lengthening of a Precice nail left in situ have been described previously in the literature. ${ }^{27}$ As described in our technique, we have used the same nail for more than one cycle of lengthening then retrograde transport without failure. At the time of writing, seven cycles of transport have been performed in three patients. We have not used a nail for more than two cycles; this is because in the patient who required three stages of transport, the nail needed to be replaced for a shorter device for the third stage. At each procedure, it is prudent to have replacement nails available in case of mechanical failure on testing, when the nail would need to be replaced. 


\begin{tabular}{|c|c|c|c|c|c|c|c|c|}
\hline Patient & Age (years) & Gender & Other injuries & $\begin{array}{l}\text { Bone loss } \\
(\mathrm{mm})\end{array}$ & $\begin{array}{l}\text { Time from } \\
\text { debridement to } \\
\text { transport }\end{array}$ & $\begin{array}{l}\text { Transport time } \\
\text { (days) }\end{array}$ & $\begin{array}{l}\text { Number of } \\
\text { transport } \\
\text { periods }\end{array}$ & Complications \\
\hline 1 & 25 & $M$ & $\begin{array}{l}\text { Right open (Gustilo } 3 \mathrm{~A} \text { ) } \\
\text { femoral fracture. Right } \\
\text { acetabulum, right pilon, } \\
\text { right patella, left knee } \\
\text { PCL, liver laceration }\end{array}$ & 160 & 10 weeks & 165 & 3 & $\begin{array}{l}\text { Knee stiffness, } \\
\text { tibial fracture on } \\
\text { manipulation }\end{array}$ \\
\hline 2 & 37 & M & $\begin{array}{l}\text { Bilateral open (Gustilo } \\
3 \mathrm{~A} \text { ) femoral fractures. } \\
\text { Bilateral rib fracture, } \\
\text { pneumothorax, right- } \\
\text { sided patella fracture, } \\
\text { olecranon fracture, } \\
\text { undisplaced talus fracture, } \\
\text { right hallux distal phalanx } \\
\text { fracture. Left subclavian } \\
\text { pseudoaneurysm, and } \\
\text { subdural and mesenteric } \\
\text { hematomas }\end{array}$ & 70 & 8 weeks & 84 & 2 & None \\
\hline 3 & 31 & M & $\begin{array}{l}\text { Isolated right open } \\
\text { (Gustilo 3A) femoral } \\
\text { fracture }\end{array}$ & 80 & 8 weeks & 90 & 2 & None \\
\hline
\end{tabular}

Representing the senior author's experience from a small series of three patients, this technique description acts a proof of concept, rather than a demonstration of safety and effectiveness. The outcomes for this, and all internal bone transport cases, must be followed as technology advances, to ensure the techniques are developed and refined with further experience. We believe the ability to bear weight early in the transport process and perform more both active and passive physiotherapy exercises contributed to earlier return of range of motion and allowed earlier self-care. The aim was for the return to function to be determined by the recovery from the polytrauma as a whole, and not necessarily delayed by a lengthy bone transport process. The transport and consolidation indices are to an extent irrelevant, as full weight bearing and joint mobilization are allowed very early in the treatment.

There is rapid development in the technology surrounding lengthening nails, which may well soon obviate the need for additional extramedullary fixation to control deformity in patients with massive bone loss. At the present time, we believe this method is a useful addition to the current methods of controlling bone transport while avoiding external fixation.

\section{TIPS AND TRICKS}

- We recommended overreaming the transport segment to the largest diameter possible and select of the smallest diameter nail $(8.5 \mathrm{~mm})$ in order to avoid jamming of the transport segment, which is slightly curved, on the nail that is straight. The small nail diameter is not an issue as the nail has no structural role in this technique.

- The proximal-medial skin incision is made $3-4 \mathrm{~cm}$ medial to the intermuscular plane, so as to allow easier skin retraction for medial to lateral drilling during the application of the medial plate proximal screws (Fig. 3).

- Distally the nail can be locked through the lateral plate with a locking screw from the large fragment plating set, as the screws are of same diameter as the locking bolts of the nail $(5 \mathrm{~mm})$. This is relatively easy to achieve by drilling through the aiming arm of the nail into a locking hole of the lateral plate.

- If a docking site grafting procedure is planned, it is recommended by the senior author that it should be performed at the same time as the nail removal. Routine nail removal is recommended by the manufacturer. At this stage, the nail has a limited structural role, and the transport segment can be locked to the lateral plate.

\section{Conclusion}

Use of a magnetic lengthening nail and double plating as a method of all internal bone transport provides an option for the management of massive femoral bone loss, while avoiding some of the challenges that have been reported with the existing techniques.

\section{Clinical Significance}

This technique provides an additional method in the armamentarium of the surgeon treating massive femoral bone loss.

\section{References}

1. Masquelet AC, Begue T. The concept of induced membrane for reconstruction of long bone defects. Orthop Clin North Am 2010;41(1):27-37. DOI: 10.1016/j.ocl.2009.07.011; table of contents.

2. Minami A, Kasashima T, Iwasaki N, et al. Vascularised fibular grafts. an experience of 102 patients. J Bone Joint Surg Br 2000;82(7):1022-1025. DOI: 10.1302/0301-620x.82b7.10332.

3. Davda K, Heidari N, Calder P, et al. 'Rail and Nail' bifocal management of atrophic femoral nonunion. Bone Joint J 2018;100-B(5):634-639. DOI: 10.1302/0301-620X.100B5.BJJ-2017-1052.R1.

4. Pallaro J, Angelliaume A, Dunet B, et al. Reconstruction of femoral bone loss with a monoplane external fixator and bone transport. 
Orthop Traumatol Surg Res 2015;101(5):583-587. DOI: 10.1016/ j.otsr.2015.04.001.

5. Wan J, Ling L, Zhang XS, et al. Femoral bone transport by a monolateral external fixator with or without the use of intramedullary nail: a single-department retrospective study. Eur J Orthop Surg Traumatol 2013;23(4):457-464. DOI: 10.1007/s00590-012-1008-x.

6. lacobellis C, Berizzi A, Aldegheri R. Bone transport using the llizarov method: a review of complications in 100 consecutive cases. Strategies Trauma Limb Reconstr 2010;5(1):17-22. DOI: 10.1007/s11751010-0085-9.

7. Paley D, Catagni MA, Argnani F, et al. llizarov treatment of tibial nonunions with bone loss. Clin Orthop Relat Res 1989(241):146-165. DOI: 10.1097/00003086-198904000-00017.

8. Napora JK, Weinberg DS, Eagle BA, et al. Hexapod stacked transport for tibial infected nonunions with bone loss: long-term functional outcomes. J Orthop Trauma 2018;32(1):e12-e18. DOI: 10.1097/ BOT.0000000000001005.

9. Maffulli N, Nele U, Matarazzo L. Changes in knee motion following femoral and tibial lengthening using the llizarov apparatus: a cohort study. J Orthop Sci 2001;6(4):333-338. DOI: 10.1007/s007760100028.

10. Landge V, Shabtai L, Gesheff M, et al. Patient satisfaction after limb lengthening with internal and external devices. J Surg Orthop Adv 2015;24(3):174-179. DOI: 10.3113/JSOA.2015.0174.

11. Simpson $A H$, Cole $A S$, Kenwright J. Leg lengthening over an intramedullary nail. J Bone Joint Surg Br 1999;81(6):1041-1045. DOI: 10.1302/0301-620x.81b6.9359.

12. Rozbruch SR, Kleinman D, Fragomen AT, et al. Limb lengthening and then insertion of an intramedullary nail: a case-matched comparison. Clin Orthop Relat Res 2008;466(12):2923-2932. DOI: 10.1007/s11999008-0509-8.

13. Nayagam S, Davis B, Thevendran G, et al. Medial submuscular plating of the femur in a series of Paediatric patients: a useful alternative to standard lateral techniques. Bone Joint J 2014;96-B(1):137-142. DOI: 10.1302/0301-620X.96B1.28691.

14. Kold S, Christensen KS. Bone transport of the tibia with a motorized intramedullary lengthening nail - a case report. Acta Orthop 2014;85(2):211-213. DOI: 10.3109/17453674.2014.887953.

15. Barinaga G, Beason AM, Gardner MP. Novel surgical approach to segmental bone transport using a magnetic intramedullary limb lengthening system. J Am Acad Orthop Surg 2018;26(22):e477-e482. DOI: 10.5435/JAAOS-D-17-00487.

16. Olesen UK, Nygaard T, Prince DE, et al. Plate-assisted bone segment transport with motorized lengthening nails and locking plates: A technique to treat femoral and tibial bone defects. J Am Acad Orthop Surg Glob Res Rev 2019;3(8):e064. DOI: 10.5435/ JAAOSGlobal-D-19-00064.

17. Silk Z, Vris A. Novel method to create a bespoke cement spacer for use in the management of segmental long-bone defects. Ann R Coll Surg Engl 2019;101(7):530-532. DOI: 10.1308/rcsann.2019.0074.
18. Tetsworth K, Paley D, Sen C, et al. Bone transport versus acute shortening for the management of infected tibial non-unions with bone defects. Injury 2017;48(10):2276-2284. DOI: 10.1016/j. injury.2017.07.018.

19. Sen $C$, Demirel $M$, Saglam $Y$, et al. Acute shortening versus bone transport for the treatment of infected femur non-unions with bone defects. Injury 2019(11):2075-2083. DOI: 10.1016/j.injury.2019.08.021.

20. Holm I, Nordsletten L, Steen $\mathrm{H}$, et al. Muscle function after midshaft femoral shortening. A prospective study with a two-year follow-up. J Bone Joint Surg Br 1994;76(1):143-146. DOI: 10.1302/0301620X.76B1.8300660.

21. Barker KL, Simpson AH. Recovery of function after closed femoral shortening. J Bone Joint Surg Br 2004;86(8):1182-1186. DOI: 10.1302/0301-620x.86b8.15194.

22. Baumgart $R$, Betz $A$, Schweiberer $L$. A fully implantable motorized intramedullary nail for limb lengthening and bone transport. Clin Orthop Relat Res 1997(343):135-143. DOI: 10.1097/00003086199710000-00023.

23. Calder PR, Laubscher M, Goodier WD. The role of the intramedullary implant in limb lengthening. Injury 2017;48(Suppl 1):S52-S58. DOI: 10.1016/j.injury.2017.04.028.

24. Guichet JM, Deromedis B, Donnan LT, et al. Gradual femoral lengthening with the albizzia intramedullary nail. J Bone Joint Surg Am 2003;85(5):838-848. DOI: 10.2106/00004623-20030500000011.

25. Kirane YM, Fragomen AT, Rozbruch SR. Precision of the PRECICE internal bone lengthening nail. Clin Orthop Relat Res 2014;472(12):3869-3878. DOI: 10.1007/s11999-014-3575-0.

26. Schiedel FM, Vogt B, Tretow HL, et al. How precise is the PRECICE compared to the ISKD in intramedullary limb lengthening? Reliability and safety in 26 procedures. Acta Orthop 2014;85(3):293-298. DOI: 10.3109/17453674.2014.913955.

27. Couto A, Freitas J, Alegrete $\mathrm{N}$, et al. Two consecutive limb lengthenings with the same PRECICE nail: a technical note. Strategies Trauma Limb Reconstr 2018;13(3):199-204. DOI: 10.1007/s11751-018-0317-y.

28. Laubscher M, Mitchell C, Timms A, et al. Outcomes following femoral lengthening: an initial comparison of the Precice intramedullary lengthening nail and the LRS external fixator monorail system. Bone Joint J 2016;98-B(10):1382-1388. DOI: 10.1302/0301620X.98B10.36643.

29. Calder PR, McKay JE, Timms AJ, et al. Femoral lengthening using the Precice intramedullary limb-lengthening system: outcome comparison following antegrade and retrograde nails. Bone Joint J 2019;101-B(9):1168-1176. DOI: 10.1302/0301-620X.101B9.BJJ-20181271.R1.

30. Foong B, Panagiotopoulou VC, Hothi HS, et al. Assessment of material loss of retrieved magnetically controlled implants for limb lengthening. Proc Inst Mech Eng H 2018;232(11):1129-1136. DOI: 10.1177/0954411918806329. 